Маралов Владимир Георгиевич

д-р психол. наук, профессор

Садардинова Светлана Николаевна

магистрант

ФГБОУ ВО «Череповецкий государственный университет» г. Череповец, Вологодская область

DOI $10.31483 / r-21896$

\title{
ПСИХОЛОГИЧЕСКИЕ ОСОБЕННОСТИ ВЗАИМОСВЯЗИ
}

РАЗДРАЖИТЕЛЬНОСТИ К ЛЮДЯМ С ПРОЯВЛЕНИЯМИ АГРЕССИИ В ПОДРОСТКОВОМ ВОЗРАСТЕ

Аннотация: статья посвящена эмпирическому исследованию взаимосвязи раздражительности к людям с формами проявления агрессии в подростковом возрасте. В результате было установлено, что высокий уровень раздражительности к людям может непосредственно перерастать в проявления различных форм агрессии. Превалирование той или иной формы определяется качественными характеристиками людей, которые способны вызывать раздражение у подростков. Полученные результаты могут быть использованы в процессе формирования у подростков способности к ненасильственному взаимодействию.

Ключевые слова: агрессивность, раздражительность, формь агрессии, подростки, сверстники, взрослье, характеристики личности.

\section{Введение}

Проблема человеческих взаимоотношений является одной из актуальных проблем современной психологии. От того, как выстраиваются эти взаимоотношения, во многом зависит эффективность взаимодействия, достижение совместных целей. Как известно, позитивные отношения людей друг к другу создают благоприятные условия для осуществления деятельности, способствуют оптимальному функционированию коллектива. Негативные, напряженные и конфликтные отношения, наоборот, являются препятствующими для взаимопонимания, оказывают дестабилизирующее влияние на деятельность. Способность к 
выстраиванию отношений с другими людьми формируется уже с раннего детства. Особое значение в этом плане приобретает подростковый возраст. Здесь закладываются базовые установки, определяющие дифференциацию отношения к людям. Подростки очень чувствительны к тому, как их оценивают другие люди, особенно сверстники, насколько они ими принимаются или не принимаются. В силу чего актуализируются мотивы поведения, связанные с самоутверждением и признанием собственной личности со стороны других людей.

Раздражительность выступает в качестве индикатора, сигнализирующего о нарушении взаимоотношений с другими людьми. Иными словами, данное состояние возникает тогда, когда в поведении или личностных проявлениях людей что-то не устраивает индивида. В настоящее время даются различные определения раздражительности [1-3]. Если попытаться их обобщить, то раздражение можно определить как негативное эмоциональное состояние, возникающее в ответ на обнаружение несоответствия внешних стимулов, событий, ситуаций, поведения людей, ожиданиям личности. В том случае, когда это состояние становится устойчивым, то оно может перерастать в раздражительность как черту личности. В современной психологии можно выделить ряд направлений исследования раздражительности. Во-первых, раздражительность изучается как одна из форм проявления агрессивности [6]. Во-вторых, раздражительность выступает в качестве признака сопутствующего целому ряду заболеваний [5; 11]. В-третьих, раздражительность может характеризовать негативное состояние человека в процессе осуществления им трудовой деятельности [7]. В-четвертых, особое внимание уделяется феномену раздражительности как формы, дестабилизирующей отношения с другими людьми [9; 10].

В наших исследованиях [3; 8] было обнаружено, что высокий уровень раздражительности способствует принятию личностью позиции принуждения, которая в своих крайних проявлениях находит выражение в агрессивных действиях, а умение не раздражаться - обусловливает принятие позиции ненасилия. В соответствии с этим возникает вопрос: «В какие формы агрессии чаще всего может перерастать раздражительность и зависит ли это от того, какие конкретно 
люди способны у личности вызывать раздражение?». Необходимость ответа на этот вопрос и побудило нас к организации специального исследования, цุель которого состояла в выявлении взаимосвязи раздражительности к людям с проявлениями агрессивности личности. В качестве гипотезы выступило предположение о том, что высокий уровень раздражительности к определенным категориям людей будет способствовать проявлениям различных форм агрессии.

Всего в исследовании приняло участие 106 учащихся одной из школ г. Череповца в возрасте 14-15 лет. Раздражительность к людям изучалась с помощью опросника В.Г. Маралова и В.А. Ситарова, адаптированного к подростковому возрасту. Причем отдельно изучался уровень раздражительности к сверстникам и уровень раздражительности к взрослым. Выраженность различных форм агрессивности исследовалась с помощью теста агрессивности Л. Г. Почебут. С целью обработки полученных результатов использовался корреляционный анализ. Применялся дихотомический коэффициент корреляции Пирсона.

\section{Результатьл}

Обратимся непосредственно к результатам исследования. Рассмотрим, прежде всего, взаимосвязь форм агрессивности с характеристиками сверстников, которые вызывают раздражение у школьников. Результаты отражены в рисунке 1. Приведены только корреляционные связи, значимые не ниже 5\% уровня значимости. 


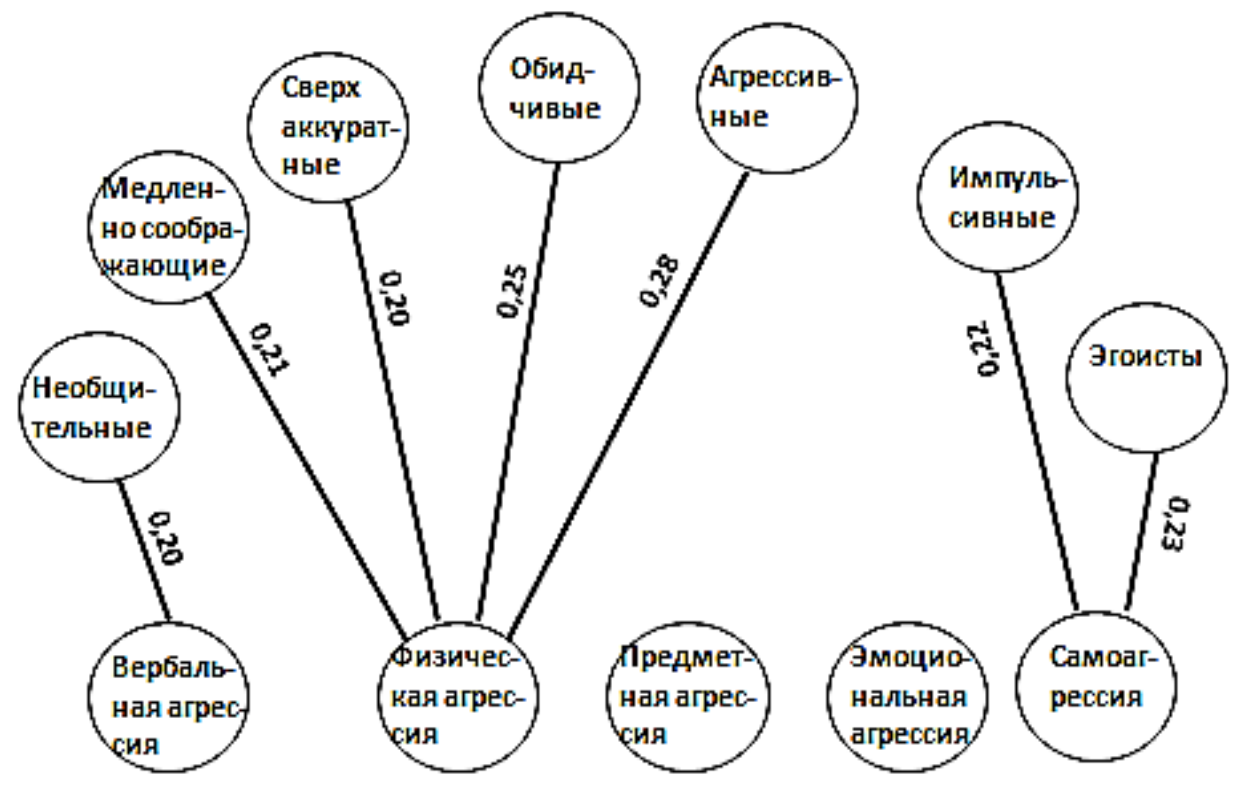

Рис. 1. Взаимосвязь форм агрессии с характеристиками сверстников, вызывающих раздражение

Как видно из рисунка 1, наибольшее число взаимосвязей обнаружено между физической агрессией и высоким уровнем раздражительности по отношению к агрессивным $(\varphi=0,28$, при $p \leq 0,01)$, обидчивым $(\varphi=0,25$, при $p \leq 0,01)$, медленно соображающим $(\varphi=0,21$, при $\mathrm{p} \leq 0,05)$ и сверх аккуратным $(\varphi=0,20$, при $\mathrm{p} \leq$ $0,05)$ сверстникам. Преобладание физической агрессии как способа снятия психического напряжения (раздражительности) в старшем подростковом возрасте вполне понятно, и объясняется особенностями данного возрастного периода. В одном случае, физическая агрессия проявляется как ответная защитная реакция по отношению к таким же агрессивным сверстникам. В другом случае, - выступает как способ утверждения себя в ситуациях, когда раздражение вызывают медленно соображающие, сверх аккуратные или обидчивые школьники. Вербальная агрессия чаще всего возникает, когда раздражение вызывают необщительные, замкнутые в себе сверстники ( $\varphi=0,20$, при $\mathrm{p} \leq 0,05)$. Задача данного вида агрессии, как-то «расшевелить» сверстника, вызвать ответную, пусть и негативную реакцию в виде обиды, плача и т. п. Самоагрессию чаще всего вызывают либо импульсивные $(\varphi=0,22$, при $\mathrm{p} \leq 0,05)$, либо черствые эгоисты ( $\varphi=$ 
0,23, при $\mathrm{p} \leq 0,05)$, неспособные к сочувствию, сопереживанию. Она вызвана неспособностью индивида активно влиять на противоположную сторону, применяя другие формы агрессии, поэтому возникающее напряжение и раздражительность снимаются самоагрессией. Предметная и эмоциональная агрессия не обнаружили положительных связей с характеристиками сверстников, вызывающих раздражение.

Аналогичным образом рассмотрим взаимосвязь различных форм агрессии с раздражительностью по отношению к взрослым людям. Результаты отражены на рисунке 2.

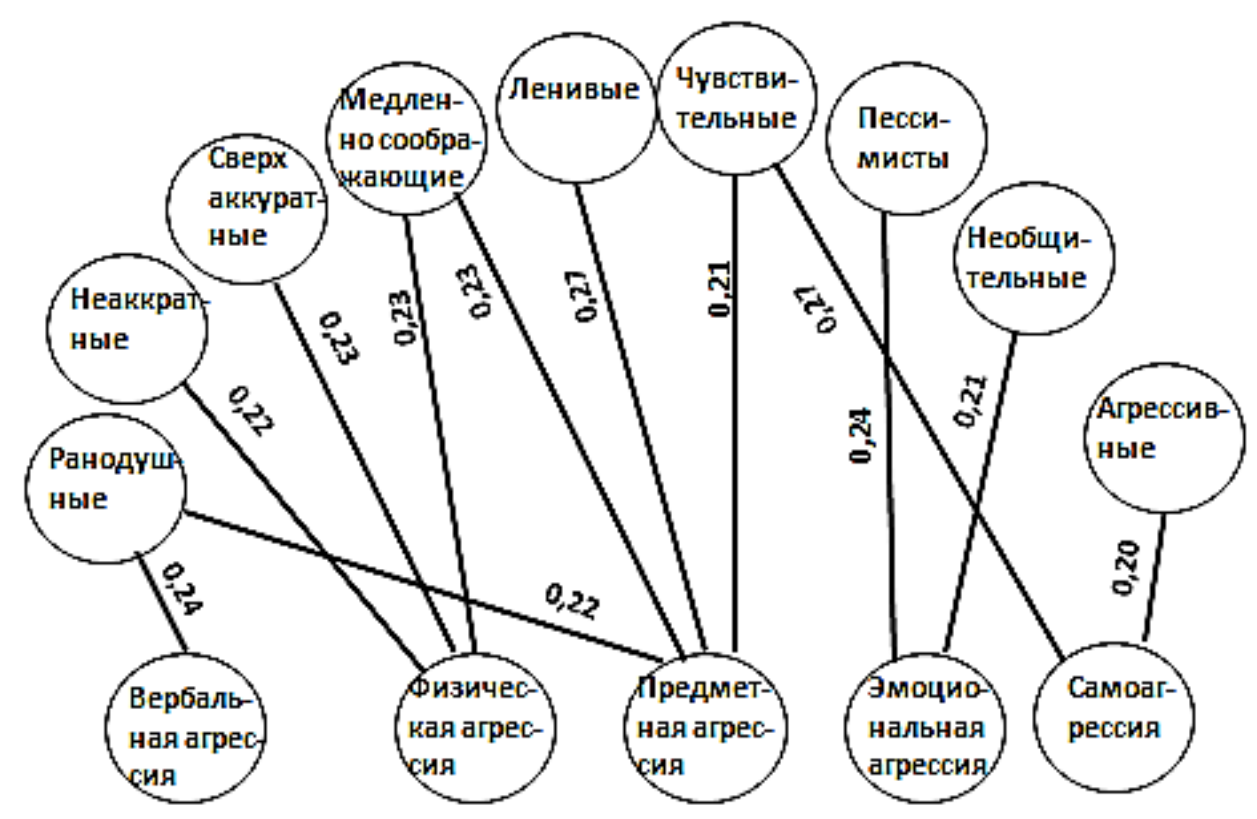

Рис. 2. Взаимосвязь форм агрессии с характеристиками взрослых, вызывающих раздражение

Из рисунка 2 хорошо видно, что чувство раздражительности, возникающее к различным категориям взрослых людей, несколько по-иному детерминирует проявления агрессии у подростков. Прежде всего, обращает на себя внимание тот факт, что здесь существенно актуализируется предметная агрессия, которую мы не наблюдали в случае, когда раздражение вызывают сверстники. Предметная агрессия проявляется в тех случаях, когда раздражение начинают вызывать ленивые ( $\varphi=0,27$, при $p \leq 0,01)$, медленно соображающие $(\varphi=0,23$, при $p \leq 0,01)$, 
эмоционально чувствительные $(\varphi=0,21$, при $\mathrm{p} \leq 0,05)$ и равнодушные $(\varphi=0,22$, при $\mathrm{p} \leq 0,05)$ взрослые. Невозможность позитивно отреагировать со стороны подростков на поведение взрослых, вызывающих раздражение, часто рождает чувство досады, которое и находит выход в предметной агрессии. Физическую агрессию взрослые могут вызывать своим внешним видом (неаккуратные $-\varphi=$ $0,22$, при $\mathrm{p} \leq 0,05$ и сверх аккуратные $-\varphi=0,23$, при $\mathrm{p} \leq 0,01)$ или несообразительностью $(\varphi=0,23$, при $\mathrm{p} \leq 0,01)$. Разумеется, такая агрессия редко когда направлена непосредственно на взрослого человека, чаще всего агрессивный потенциал вымещается на более доступных объектах, например, на младших детях или на сверстниках, которые не могут ответить тем же. Равнодушные, безучастные к делам подростка взрослые чаще всего вызывают вербальную агрессию ( $\varphi$ $=0,24$, при $\mathrm{p} \leq 0,01)$, которая выражается в препирательстве, ругани и т. п. Пессимистически настроенные взрослые $(\varphi=0,24$, при $\mathrm{p} \leq 0,01)$ или не склонные к общению ( $\varphi=0,21$, при $\mathrm{p} \leq 0,05)$ чаще всего способны вызвать эмоциональную агрессию, которая выражается в различных аффективных реакциях. Наконец, самоагрессия положительно коррелирует с раздражительностью по отношению к агрессивным взрослым ( $\varphi=0,20$, при $\mathrm{p} \leq 0,05)$ и эмоционально чувствительным $(\varphi=0,27$, при $\mathrm{p} \leq 0,01)$. В первом случае, самоагрессия вызвана невозможностью адекватно ответить взрослому, в другом, - может возникать из-за чувства вины или отчаяния.

\section{Bblвoдbl}

На основе всего сказанного можно сделать ряд важных выводов. Во-первых, было установлено, что высокий уровень раздражительности к людям может непосредственно перерастать в проявления различных форм агрессии. Во-вторых, превалирование той или иной формы определяется качественными характеристиками людей, которые могут вызывать раздражение у подростков. В-третьих, одна и та же личностная характеристика личности, вызывающая раздражение, может детерминировать разные формы агрессии в зависимости от того, кто вызывает раздражение - сверстник или взрослый. Например, агрессивный сверстник, вызывающий раздражение, побуждает к ответной физической 
агрессии, а агрессивный взрослый, также вызывающий раздражение, чаще стимулирует самоагрессию. В-четвертых, было установлено, что по отношению к сверстникам, вызывающим чувство раздражения, чаще применяется физическая агрессия, а по отношению к взрослым - предметная агрессия.

В заключение следует отметить, что необходимо проводить специальную работу с подростками по осознанию ими уровня своей раздражительности к людям и причин, вызывающих такое раздражение, формировать способность к сдержанности и самоконтролю, развивать навыки ненасильственного взаимодействия с людьми.

\section{Список литературы}

1. Большой медицинский словарь [Электронный ресурс]. - Режим доступа: http://alcala.ru/medicinskij-slovar/slovar-R/index.shtml (дата обращения: 21.08.2017).

2. Жмуров В.А. Большой толковый словарь терминов психиатрии. - Элиста: Джангар, 2010. - 864 с. [Электронный ресурс]. - Режим доступа: https://psycliniccenter.ru/biblioteka-kliniki/tolk-slovar-terminov-psikhiatrii/rabd-rapt (дата обращения: 39.11 .2018$)$.

3. Корягина И.И. Сравнительная характеристика позиций взаимодействия у студентов-медиков и студентов - будущих специалистов сферы психолого-педагогического сопровождения / И.И. Корягина, В.Г. Маралов, В.А. Ситаров // Образование и наука. - 2018. - Т. 20. - №5. - С. 79-104 [Электронный ресурс]. Режим доступа: https://elibrary.ru/item.asp?id=35022000 (дата обращения 26.11.2018)

4. Энциклопедический словарь по психологии и педагогике [Электронный pecypc]. - Режим доступа: http://psychology_pedagogy.academic.ru/ (дата обращения: 21.08.2017).

5. Angelelli P., Paolucci S., Bivona U., Piccardi L., Ciurli P., Cantagallo A., Antonucci G., Fasotti L., Di Santantonio A., Grasso M.G., Pizzamiglio L. Development of neuropsychiatric symptoms in post stroke patients: a cross-sectional study // Acta 
Psychiatrica Scandinavica. - 2004. - T. 110. - No 1. - P. 55-63. DOI: 10.1111/j.16000447.2004.00297.x

6. Buss A. The psychology of aggression. - N.Y.; London: Wiley and Sons, 1961. -307 p.

7. Jackson D.L. Correlates of physical and emotional health among male and female workaholics. - 1993 [Electronic resource]. - Access mode: https://elibrary.ru/item.asp?id=5782405 (retrieved: 08.05.2018).

8. Maralov V.G., Sitarov V.A. Person-oriented irritability, social and educational stereotypes as factor of adopting controlling or non-aggressive position by students // International Journal of Pharmaceutical Research and Allied Sciences. - 2018. - T. 7. №2. - P. 74-85.

9. Pollock T. A personal file of stimulating ideas problem solvers // Supervision. 1991. - T. 52. - №5. - P. 24-26.

10. Pridmore S., Skerritt P., Ahmadi Ja. Why do doctors dislike treating people with somatoform disorder? // Australasian Psychiatry. - 2004. - T. 12. - №2. - P. 134138. DOI: 10.1111/j.1039-8562.2004.02085.x

11. Yuen L.D., Shah S., Do D., Miller Sh., Wang Po.W., Hooshmand F., Ketter T.A. Current irritability associated with hastened depressive recurrence and delayed depressive recovery in bipolar disorder // International Journal of Bipolar Disorders. 2016. - T. 4. - No 1. - C. 15. DOI: 10.1186/s40345-016-0056-2 